\title{
New information on the cranial and postcranial anatomy of the early synapsid Ianthodon schultzei (Sphenacomorpha: Sphenacodontia), and its evolutionary significance
}

\author{
F. Spindler ${ }^{1}$, D. Scott ${ }^{2}$, and R. R. Reisz ${ }^{2}$ \\ ${ }^{1}$ TU Bergakademie Freiberg, Institut für Geologie, Bernhard-von-Cotta-Straße 2, 09599 Freiberg, Germany \\ ${ }^{2}$ Department of Biology, University of Toronto Mississauga, 3359 Mississauga Road, Mississauga, Ontario, L5L 1C6, Canada \\ Correspondence to: F. Spindler (mail@frederik-spindler.de), D. Scott (diane.scott@utoronto.ca), \\ and R. R. Reisz (robert.reisz@utoronto.ca)
}

Received: 30 April 2014 - Revised: 3 August 2014 - Accepted: 5 August 2014 - Published: 6 October 2014

\begin{abstract}
Newly identified material belonging to the holotype specimen of Ianthodon schultzei substantially increases our knowledge of this poorly known basal sphenacodont synapsid from the fossil site in Garnett, Kansas (Missourian, Late Pennsylvanian). The original description, based on a partial dermal skull roof, is augmented with information on the palate and braincase, together with data on the mandible and a few postcranial elements. The known skeletal morphology resembles that of Haptodus garnettensis, another synapsid taxon known from this locality, but with fewer marginal, distinctly recurved teeth and smaller teeth on the transverse flange of the pterygoid. Although recognizing that the holotype and only known specimen represents a juvenile individual, Ianthodon appears to reflect a more basal sphenacodontian condition than $H$. garnettensis. A restricted phylogenetic analysis based on previous work and newly scored characters for Ianthodon, Cutleria and Pantelosaurus supports this hypothesis. The Garnett locality appears to preserve an assemblage of synapsids (Haptodus, Ianthasaurus, Ianthodon) that are close to the base of the large clade that includes Edaphosauridae and Sphenacodontia, suggesting that an initial diversification of this clade occurred well within the Carboniferous Period.
\end{abstract}

\section{Introduction}

The Garnett locality in Kansas has produced one of the best known Missourian-age continental fossil assemblages, including plants and pollen, invertebrates, fishes, amphib- ians, and amniotes. Its geology and the vertebrate biota have been summarized by Reisz et al. (1982) and Kissel and Reisz (2004). The tetrapod assemblage is characterized by the presence of numerous skeletons of the oldest known diapsid reptile Petrolacosaurus (Reisz, 1977, 1981) and multiple skeletons of several synapsids, including an undescribed ophiacodontid, an undescribed sphenacodontian, the small edaphosaurid Ianthasaurus hardestiorum (Reisz and Berman, 1986; Modesto and Reisz, 1990; Mazierski and Reisz, 2010) and the basal sphenacodontian Haptodus garnettensis (Currie, 1977; Laurin, 1993). Although originally identified as a synapsid, the precise identity of Xyrospondylus ecordi, known only from the holotype dorsal vertebra (KUVP 9963, University of Kansas Museum of Natural History, Lawrence, KS), remains uncertain (Reisz, 1986). The diversity of synapsids at this site recently increased with the description of a single partial skull of Ianthodon schultzei (Kissel and Reisz, 2004). The synapsid assemblage at Garnett seems to document the earliest known stages of eupelycosaurian evolution, and the taxic diversity preserved at this locality suggests that a detailed reexamination of all known materials from this locality may provide new insights into patterns of diversification within this important clade. Ianthodon schultzei is a critical component of this reexamination.

The holotype of Ianthodon schultzei (Kissel and Reisz, 2004) was originally separated from a block that apparently also contained the remains of both Petrolacosaurus and Haptodus. Reexamination and additional preparation of the slabs, including the skull described originally, has revealed 
more skeletal material that can be confidently attributed to Ianthodon. We identify the synapsid material on the entire block as a single disarticulated partial skeleton of I. schultzei, accompanied by a partial Petrolacosaurus skeleton, in contrast with the previous mistaken interpretation of certain elements as belonging to Haptodus garnettensis (Kissel and Reisz, 2004). This identification is based largely on a detailed reevaluation of the available anatomical information. However, our interpretation is also supported by the following evidence: (1) there is no duplication of any of the nonPetrolacosaurus elements; (2) there is no discrepancy in size or stage of ossification among the cranial or postcranial elements that are not attributed to Petrolacosaurus; (3) it is unlikely that two synapsid skeletons of the same size and ontogenetic stage would be present without any overlap between the preserved elements. The assignment of the dentary to Haptodus garnettensis is questionable on anatomical grounds. After additional preparation and study of all known specimens from the locality, the surface texture characteristics used to identify the elements on this block as Haptodus garnettensis, as suggested by Kissel and Reisz (2004, p. 412), are rejected. Here, we provide a comprehensive redescription of I. schultzei and discuss the phylogenetic implications of this new data for sphenacodont evolution.

The following instituional codes are used in this paper: FO - University of Toronto Mississauga Fossil; KUVP - University of Kansas Museum of Natural History, Lawrence, KS; RM - Redpath Museum, Montreal; ROM - Royal Ontario Museum, Toronto; RS and SS - Sächsisches Landesamt für Umwelt, Landwirtschaft und Geologie, Freiberg (geological survey).

\section{Systematic paleontology}

Synapsida Osborn (1903)

Eupelycosauria Kemp (1982)

Sphenacomorpha Ivakhnenko (2003)

Sphenacodontia Romer and Price (1940)

Ianthodon schultzei Kissel and Reisz (2004)

Holotype. KUVP 133735 consists of a nearly complete skull including both mandibles and an anterior postcranial skeleton including vertebrae, ribs, right scapula and coracoid as well as left humerus (Fig. 1). The specimen is incompletely ossified, indicating a juvenile individual. On the same slab, a partial skeleton of Petrolacosaurus is preserved. Palatal, mandibular, occipital and postcranial elements are newly assigned to the holotype. The skull was removed from the slab during preparation (Fig. 2). After documenting the originally exposed side (Kissel and Reisz, 2004, Fig. 2), the skull was embedded and prepared from the other side, now exposing the labial surface of the maxilla (Fig. 3).
Referred specimens. KUVP 133736, left maxilla; FO 176, right maxilla. These referrals are based not only on the shape of the maxilla but also on tooth shape and the reduced number of precaniniform teeth relative to that in Haptodus garnettensis.

Revised diagnosis: Small sphenacodontian characterized by the presence of three premaxillary tooth positions and with conical marginal teeth that overlap each other at the base. It differs from Haptodus garnettensis in having fewer marginal teeth, with spaces for up to 20 teeth in the maxilla, rather than 23 . There are at least 21 tooth positions in the dentary, rather than 24. Distal marginal teeth are slenderer and more distinctly recurved than in Haptodus, with narrow, rather than bulbous, tips. It differs from $H$. garnettensis in having four or fewer maxillary teeth anterior to the enlarged pair of teeth on this element rather than six. The teeth on the transverse flange of the pterygoid are smaller than in Hapto$d u s$. It differs from other sphenacodonts in having the pineal foramen located at the midpoint of parietal length.

\subsection{Description}

Ianthodon schultzei is known from a single juvenile skeleton with delicate bones, differing from contemporary specimens of Haptodus garnettensis even when of similar size. The reconstructed skull length of Ianthodon is slightly less than 10 $\mathrm{cm}$, similar in length to the juvenile and smallest specimens RM 14,156, RM 14,157 and ROM 29872 of Haptodus garnettensis (see Currie, 1977; Laurin, 1993). As reconstructed, the skull of Ianthodon is slenderer than H. garnettensis specimens of the same size in the region of the snout and the anterior mandible. As far as can be discerned, the postcranial proportions of Ianthodon are nearly the same as in RM 14,156 , while the higher number of precaniniform maxillary teeth and the more rectangular shape of the humerus entepicondyle distinguish the holotype of $H$. garnettensis from that of Ianthodon.

The holotype skeleton is preserved on the same block with some skeletal elements of Petrolacosaurus, from which it can easily be distinguished on anatomical grounds. The humeri, although of similar size, show clear differences such as proportions and the positions of the foramen and supinator process.

\subsubsection{Skull}

The dorsal skull roof of KUVP 133735 has already been described in detail by Kissel and Reisz (2004), and this need not be repeated here. The skull elements are spread across the slabs that form the fossil block (Fig. 1), with several elements trending off the edges. Most of the skull roof is preserved on the original small block, mostly disarticulated. The nasals, quadratojugal and premaxillae have clearly moved away from the other skull elements. A concentration of palatal, occipital and mandibular elements is found 


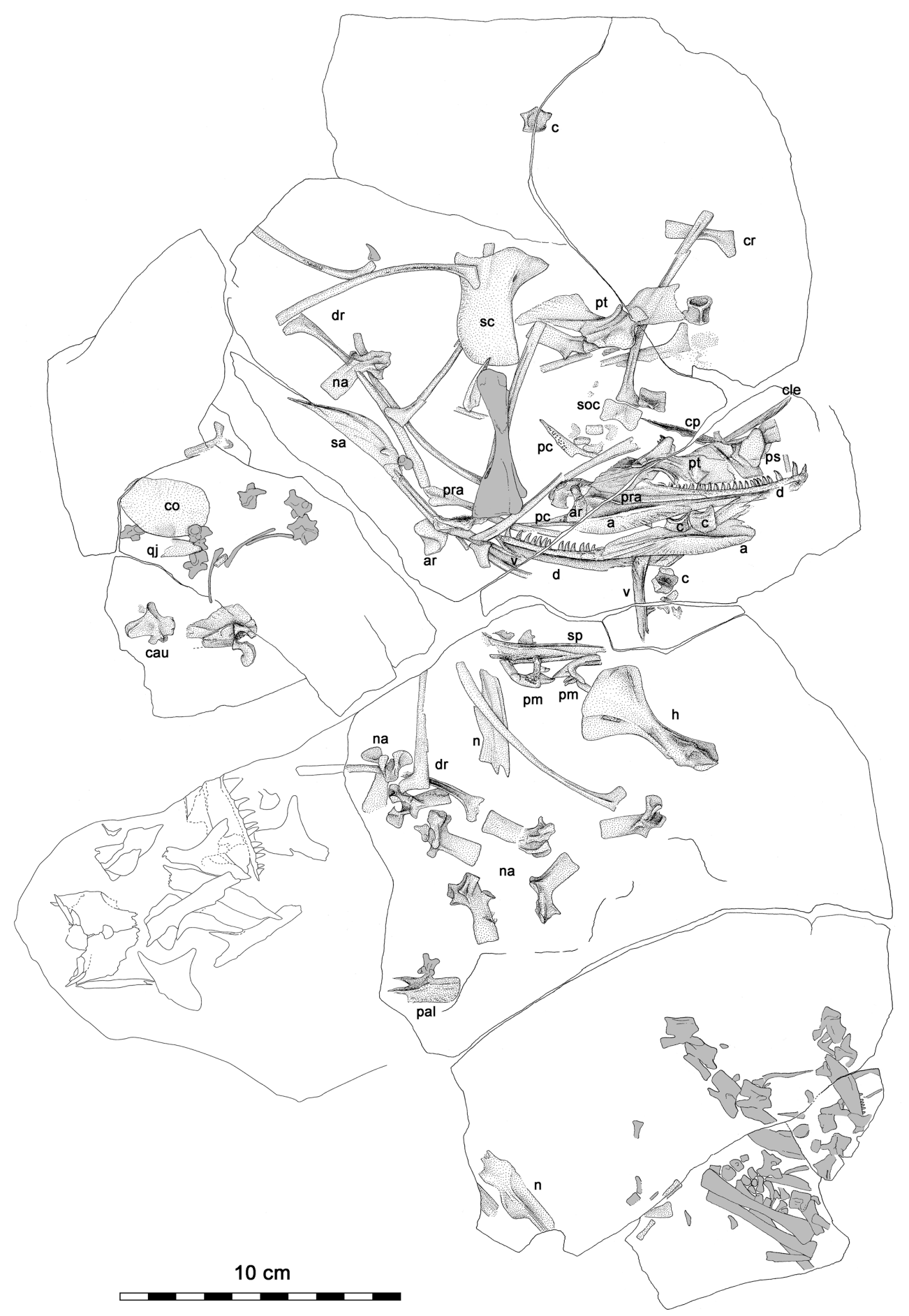

Figure 1. Ianthodon schultzei holotype KUVP 133735, combined slab, with outlines of skull bones (outlines by D. Scott, made prior to Kissel and Reisz, 2004, Fig. 2; now exposed as embedded counter slab) and a disarticulated skeleton of the diapsid reptile Petrolacosaurus kansensis (shaded areas); a - angular; ar - articular; c - vertebra centrum; cau - caudal neural arch; cle - cleithrum; co - anterior coracoid; $\mathrm{cp}$ - cultriform process of parasphenoid-basisphenoid complex; $\mathrm{cr}$ - cervical rib; $\mathrm{d}$ - dentary; $\mathrm{dr}$ - dorsal rib; $\mathrm{h}$ - humerus; $\mathrm{n}$ - nasal; na presacral neural arch; pal - palatine; pc - posterior coronoid; pm - premaxilla; pra - prearticular; ps - parasphenoid-basisphenoid complex; pt - pterygoid; qj - quadratojugal; sa - surangular; sc - scapula; soc - supraoccipital; sp - splenial; v - vomer. 


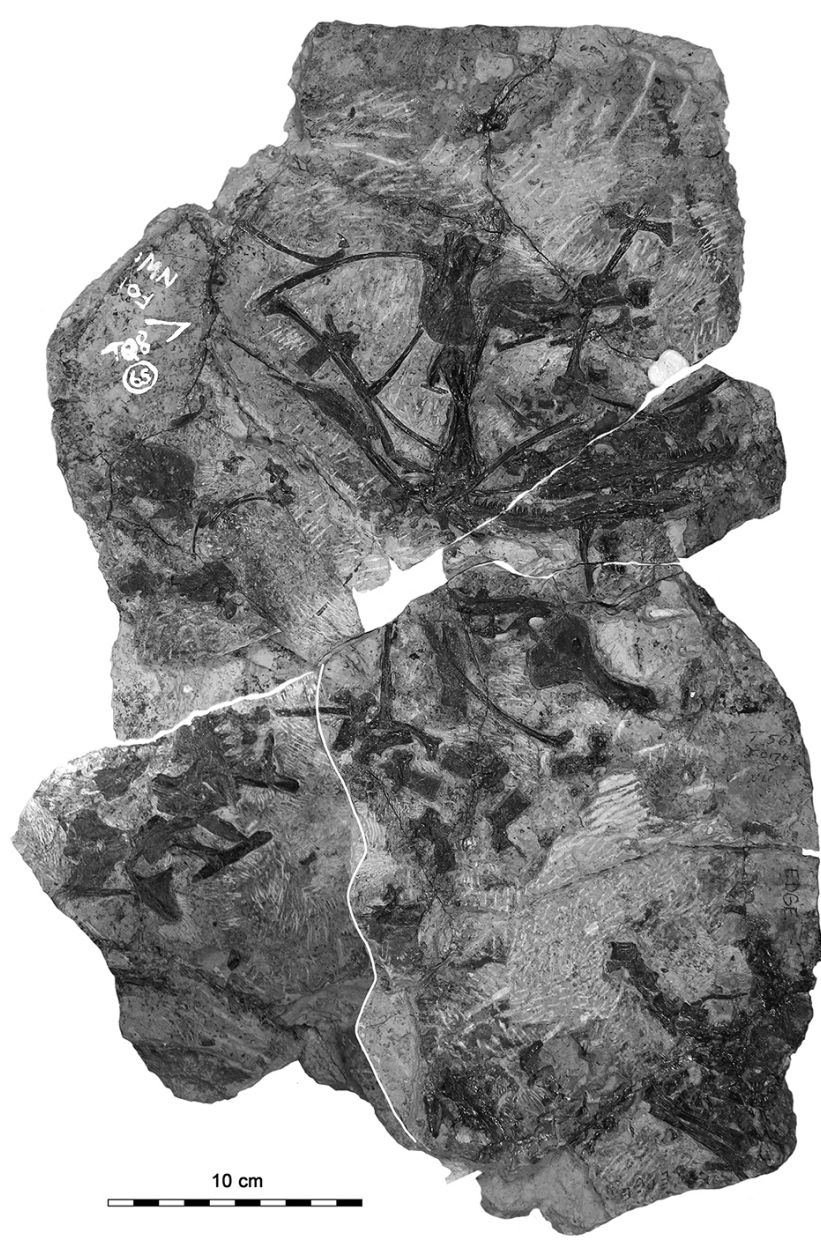

Figure 2. Ianthodon schultzei holotype KUVP 133735, slab in present condition, combined with photograph of skull area (lower left) before its removal.

in close proximity to each other on one of the other blocks, together with other skeletal elements. Partly because of the juvenile condition of the specimen, it is somewhat difficult to interpret the exact edges of some of the elements. We are, however, confident that these bones belonged to one individual because of the consistency in anatomy, level of ossification and lack of duplication.

The premaxilla is an unusually slender element, especially in view of the large size of the first tooth. All three rami of the premaxilla are slender. The nasal process is slightly broader transversely than the maxillary process, whereas the vomerine process is the smallest and most slender of the three rami. The slenderness of the maxillary process and of the body of the bone suggests that the teeth were not deeply rooted, a condition similar to that seen in the maxilla, despite the unusually large size of the first tooth. The right premaxilla, the better preserved of the pair, bears three marginal teeth. The first tooth is broad at the base, although slightly exaggerated by compression, and much taller than the second tooth. These teeth are only slightly curved posteriorly, and this curvature is restricted to the tip. The upper crowns are densely striated on the lingual side, and moderately striated on the labial side.

The maxilla of the holotype KUVP 133735 is poorly preserved, but two referred specimens provide valuable additional information about the anatomy of this element. These specimens are identified with confidence as belonging to Ianthodon because of the unique dentition that they share with the holotype. Overall, the shape of the teeth is quite unusual, not seen in other coeval amniotes. The teeth have a broad base, but very slender crowns, tapering rapidly crownward without any bulbous thickening. The slender crowns are recurved. This is in strong contrast to the teeth of Haptodus garnettensis, which are characterized by their overall robustness, as well as a slight bulbousness below the crown. These maxillae also differ from those of Haptodus in the outline of the dorsal edge and in the presence of fewer precaniniform teeth.

The dorsal blade of the maxilla is low. Best seen in the medially exposed referred specimens, it increases in height gradually along the anterior one-third of the bone and above the alveolar shelf, reaching its maximum above the enlarged pair of teeth. Its dorsal edge extends posteriorly along four or five tooth positions before it starts to slope ventrally, reaching the alveolar shelf by the nineteenth tooth position. Anteriorly, the sutural contact with the premaxilla covers most of the alveolar shelf of the first maxillary tooth. Between the second and sixth tooth positions, the alveolar shelf is smooth, defining the maxillary contribution to the elongate internal naris. There is little or no dorsal expansion of the alveolar shelf in the region of the enlarged teeth. The medioventral part of the dorsal blade is slightly swollen above the alveolar shelf but less so than in Haptodus garnettensis (RM 14,157).

The maxillary tooth count can be calculated for Ianthodon because the two referred maxillae are nearly complete. There are at least 18 positions preserved in KUVP 133736, and it is likely that there would have been up to two more tooth positions in the maxilla posteriorly. As seen in the referred specimens (Fig. 4), either three (FO 176) or four (KUVP 133736) anterior teeth increase in size towards the pair of enlarged teeth. As in other sphenacodonts, there are two tooth positions for the largest teeth of the maxilla, and, generally, their location is indicated by the center of growth on the maxilla. Posterior to this region, the teeth gradually decrease in size posteriorly. All teeth are broad at their bases, remaining largely uncurved through most of the crown, with tips curving posteriorly (Laurin, 1993). Striations are present in the presumed crown portions of the maxillary teeth. As seen in the spectrum of juvenile to adult specimens of Haptodus garnettensis, as well as other non-therapsid synapsids, significant ontogenetic changes of the tooth crown type are not to be expected.

When compared to the known maxillae of Haptodus garnettensis where a higher tooth count is present both in adult and in juvenile stages (see Currie, 1977), the reduced 


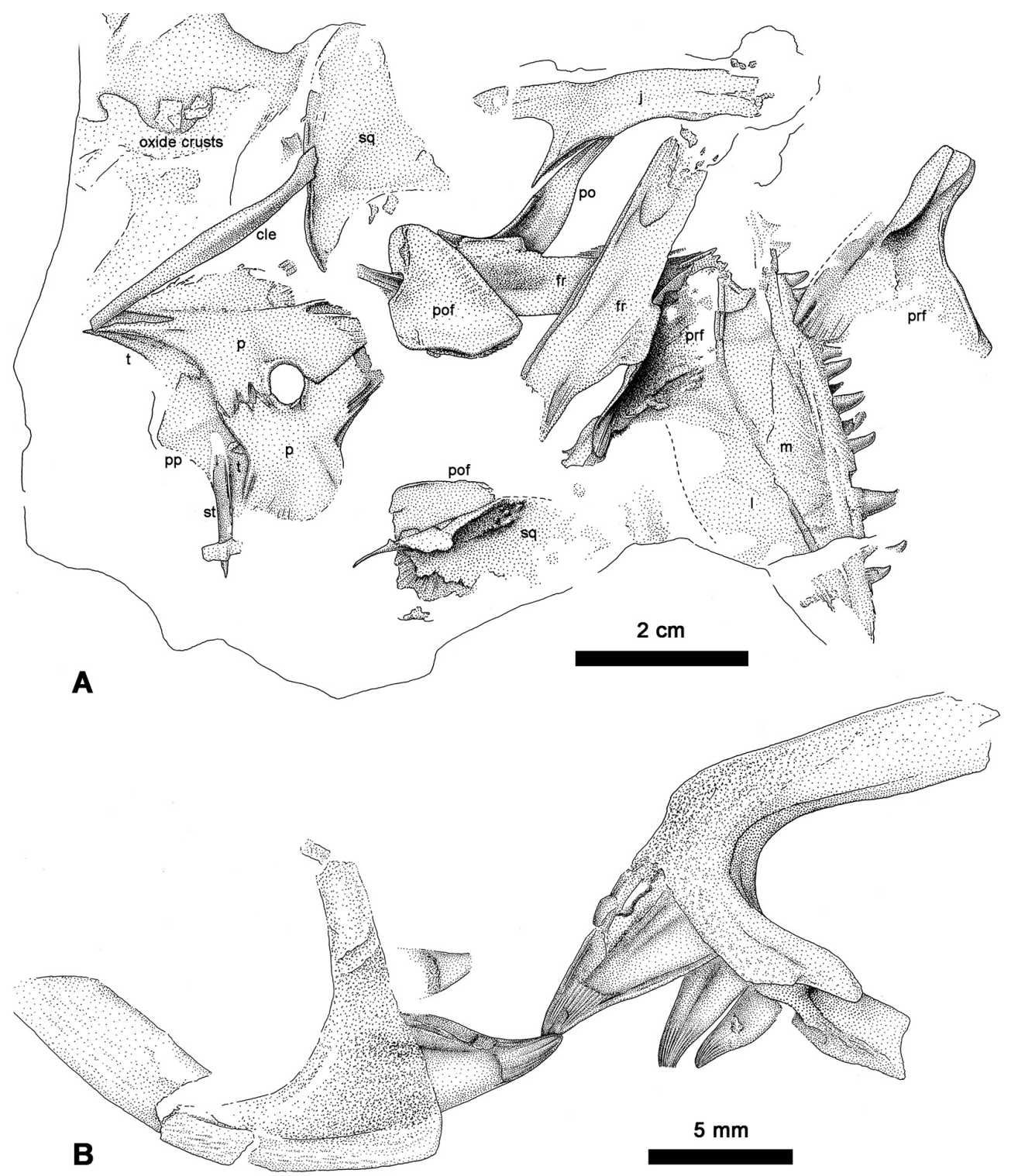

Figure 3. Ianthodon schultzei holotype KUVP 133735. (a) Redocumented skull; (b) dislocated premaxillae. Fr - frontal; j - jugal; 1 lacrimal; $\mathrm{m}$ - maxilla; $\mathrm{p}$ - parietal; po - postorbital; pof - postfrontal; pp - postparietal; prf - prefrontal; sq - squamosal; st - supratemporal; $\mathrm{t}$ - tabular.

dentition of Ianthodon is of taxonomic significance. This reduced number of maxillary teeth is related to differences in the precaniniform tooth count, a feature that appears to correspond to the reduced premaxillary tooth number in this taxon relative to the condition in $H$. garnettensis (Laurin, 1993).

The tall lacrimal of Ianthodon schultzei, despite its relatively poor preservation, is sufficiently complete for determining its outline, showing it to be as tall as the maxilla or even slightly taller. This is consistent with the lacrimal height of other basal sphenacodontians (Laurin, 1993, Fig. 3) but contrasts with the still taller lacrimal of Palaeohatteria (Credner, 1888, pl. 25, Fig. 4) and the slender elements in ophiacodontids and eothyridids. The latter basal synapsids have distinct, elongate maxilla-lacrimal sutures, and their lacrimals tend to be slender anteriorly. As in edaphosaurids and basal sphenacodontians, I. schultzei has a tall lacrimal, indicating that the snout was proportionately taller than in eothyridids or ophiacodontids. Nevertheless, details of the lacrimal foramina and its precise sutural contacts are not available for description or evaluation.

In the original description (Kissel and Reisz, 2004), the left prefrontal was identified as an element covering the maxillary tooth row, and the right was located between the lacrimal and frontal. The supraorbital bar of the "left" currently shows a ridge that may indicate the dorsal surface of the skull, and therefore this element more likely represents 


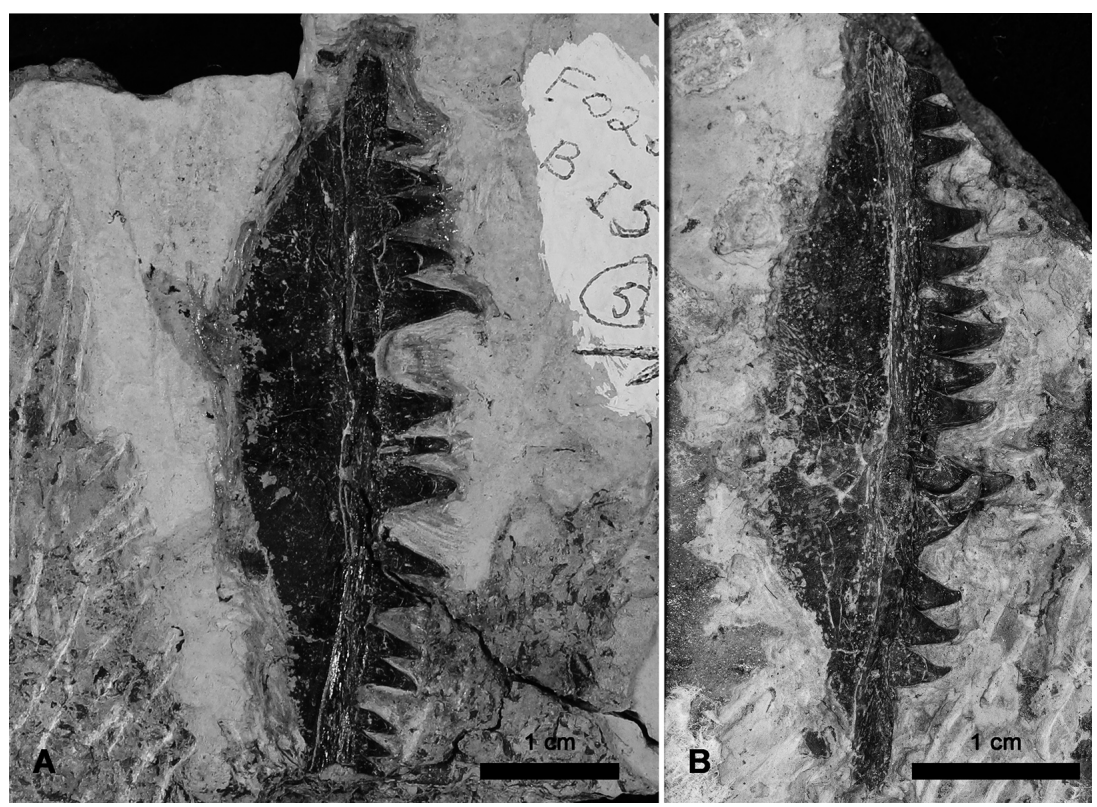

Figure 4. Ianthodon schultzei. (a) Referred left maxilla KUVP 133736; (b) referred right maxilla FO 176.

the right prefrontal. The anterior tips of the two prefrontals point toward one other and are exposed in medial view. A prefrontal pocket is now clearly observed as the depression in the innermost prefrontal in Kissel and Reisz (2004, Fig. 2).

As with many other elements, the squamosal is already well-described. However, the element identified as the left squamosal by Kissel and Reisz (2004) bears an ascending rim that might mark the inflection towards the occipital plane.

The quadratojugal is nearly complete and quite similar to those in edaphosaurids and basal sphenacodonts. The narrow ventral portion that would have touched the base of the quadrate is covered by a vertebra, but the dorsal process of the quadratojugal is exposed next to the coracoid. It is sheetlike above the ventral quadrate buttress and is slightly bifurcate at its thin dorsal end. It lacks an anterior process. Overall, its preserved portion is similar to that seen in Haptodus garnettensis and other sphenacodonts.

Both vomers can be identified, partially covered by other elements and exposed in partial dorsal view. Anteriorly, its narrow tip has a short indentation for contact with the premaxilla. This element broadens posteriorly, but is covered by the mandible. Very small teeth are observed below the lateral margin, where the vomer would have formed the medial edge of the choana.

The rough dimensions of the palatine are discernible on the central block (Fig. 5), near a series of neural arches. The choanal notch of the palatine is also exposed, although the outline of the anterior region is incomplete.

Both pterygoids are preserved. Measured from the level of the thickened transverse flange, the anterior process is about twice the length of the quadrate ramus. The dorsal blade emerging from the medial rim of the palatine ramus is as low as in Haptodus garnettensis (ROM 43606) but with a steeper posterior edge. The transverse flange bears at least three teeth. Regarding the structural similarity with the pterygoid of Haptodus garnettensis, there are most likely more tooth positions, particularly since the teeth of this row are proportionately smaller in Ianthodon. The high quadrate ramus equals the proportions seen in other basal synapsids. As is typical for basal sphenacodontians, the basipterygoid articulation lies more ventrally on the body of the pterygoid than in Dimetrodon and other sphenacodontids but more dorsally than in varanopids and ophiacodontid synapsids (compare to Romer and Price, 1940; Reisz, 1986). A peg-like process marks the area where the epipterygoid articulates with a subvertical notch in the anterior edge of the quadrate ramus, as seen also in most stem sphenacodonts (not in Palaeohatteria), Sphenacodon (Eberth, 1985, Fig. 21) and Ianthasaurus (ROM 59933, contra Mazierski and Reisz, 2010).

As with the palatine, no significant difference could be found in the parasphenoid-basisphenoid complex of Ianthodon schultzei and Haptodus garnettensis. The basipterygoid processes point anterolaterally and have flat articular facets. Compared to Haptodus garnettensis (ROM 43602, 43604), the cultriform process is proportionally longer.

The supraoccipital is subrectangular in outline, with a shallow embayment for the foramen magnum in its central margin. There is a modest vertical median ridge that widens toward the embayment, where the supraoccipital articulated with the exoccipitals on either side of the foramen magnum. Other elements of the braincase may be preserved, but are 


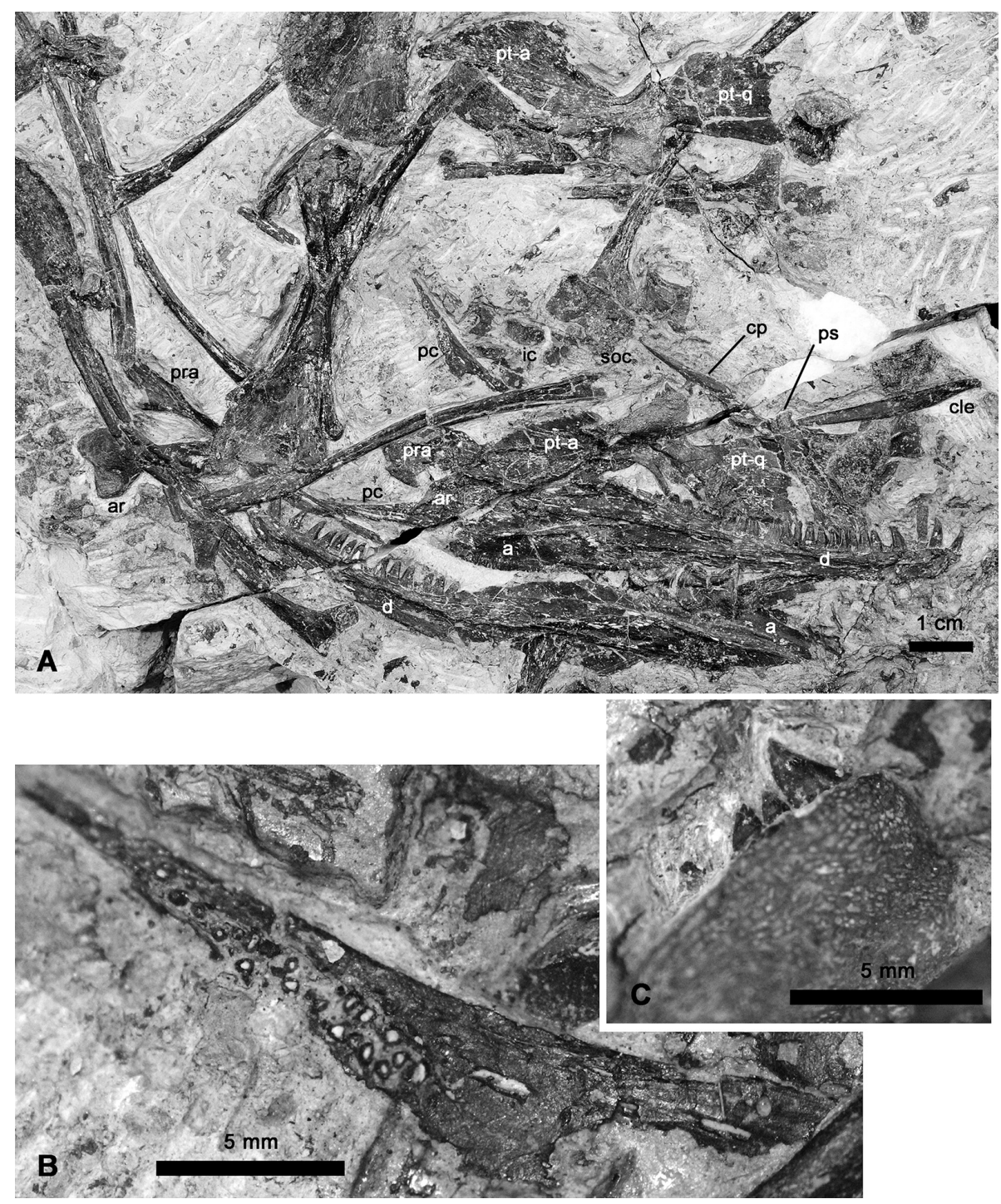

Figure 5. Ianthodon schultzei holotype KUVP 133735. (a) Close-up of central block; (b) detail of right posterior coronoid with eroded denticles; (c) detail of right pterygoid transverse flange dentition in dorsolateral aspect. Ic - intercentrum; pt-a - pterygoid anterior ramus; pt-q - quadrate ramus of pterygoid.

difficult to identify with confidence because of poor preservation.

\subsubsection{Mandible}

Both mandibles are preserved, with the better-articulated left ramus measuring approximately $84 \mathrm{~mm}$ in total length. In lateral view, the mandible is only slightly bent in its tooth-bearing anterior half. The posterior end of the dentary, together with the dislocated surangular, forms a moderate bulge of the coronoid region, resembling that of the Haptodus garnettensis specimen ROM 30099. The anterior part of the mandible is dorsoventrally slenderer than in all known specimens of Haptodus garnettensis, including the youngest known mandible in ROM 29872. This juvenile is of similar size to the Ianthodon holotype but is much more robust and shows an initial dorsoventral thickening of the symphyseal area, a region that is strong in the largest specimen ROM 43604.

The dentary is very slender in dorsoventral view, with a thickened alveolar shelf that occupies almost half the height on the lingual side. The slight concavity of the tooth margin corresponds to the moderate convexity of the maxilla. There are 21 teeth preserved, with one certain gap for an unpreserved and maybe enlarged third tooth near the tip of the left dentary. Applying the pattern of the tooth density seen in the middle region, there might be even more positions, for a possible maximum of 25 . The tooth bases are broad, but often appear to overlap each other, partly due to shape and partly due to compaction. The tooth morphology is readily 
distinguishable from that of Haptodus garnettensis both by size of the base and the narrowness of the tip (see Laurin, 1993, Fig. 4b) as well as by the overall delicate morphology of the crown. The level of compaction of the teeth and the overall reduced thickness of the dentine suggest that the teeth in Ianthodon reflect trophic specializations that are different from Haptodus. The teeth in the posterior region of the dentary increase in broadness as they become smaller posteriorly.

Dislocated from the articulated mandibles, there is a single splenial next to the premaxillae. Both the anterior and posterior tips are delicate and poorly preserved. The dorsoventral extension is high, suggesting that the splenial had a thin exposure in lateral aspect. Its posterior end has a slight dorsal expansion, possibly contributing to the coronoid eminence.

The angular of Ianthodon schultzei is slender and obviously not as tall or as massive as in Haptodus garnettensis, especially relative to the surangular height; it has a flat ventral lamina that does not extend as far below the prearticular level as in Haptodus garnettensis (compare to Laurin, 1993, Fig. 10). Both genera share the gently convex ventral edge of the angular, which is thin in cross section but not developed as a reflected lamina. Its ventral edge is marked by slight rugosities. On the medial side, the angular has a strong longitudinal bar for the prearticular contact.

The right surangular is exposed medially, showing the posterior articulation for the articular and the anterodorsal groove to host the dentary. A gently developed ridge runs along its dorsal edge where an aponeurosis would have attached for the adductor muscles. The posterior border of the adductor fossa is marked by a small triangular process for the anterodorsal process of the articular. There are no clear differences from the surangular of Haptodus garnettensis, apart from being slightly narrower dorsoventrally (Laurin, 1993, Fig. 10).

The posterior coronoid is a slender, elongate element with a narrow anterior process and a bifurcate posterior region. The body of the left posterior coronoid, exposed in medial view, is covered by more than 20 small teeth. Another denticulate coronoid element is preserved, but it is largely covered by other elements, making precise identification difficult.

Both articulars are preserved, one in articulation with the rest of the left mandible, the other isolated and displaced in front of the right dentary. No detailed observations on the presence of a pterygoideus or a retroarticular process can be made. There are extremely elongate, slender prearticulars preserved in place on the left mandible and separately from the right mandible, the latter displaced posteriorly to lie under the humerus of Petrolacosaurus and a rib. Its posterior process is slightly bifurcate. Both seem untwisted, contrasting with all edaphosaurids and basal sphenacodonts. Based on our experience with the compaction properties of bones in the Garnett fossil beds, we can determine that this is not a diagenetic artifact. Unfortunately, the juvenile Haptodus garnettensis specimen ROM 29872 is not exposed for direct comparison, but the rather adult ROM 30099 has a twisted prearticular. Thus, the Ianthodon prearticular appears to preserve the plesiomorphic condition. Along with the articular, the main body of the prearticular is strongly built, and, despite its juvenile stage, the articular is well ossified and suggests that it had large quadrate condyles, although not preserved on the slab.

\subsubsection{Postcranial skeleton}

Several elements of the postcranial axial skeleton, mostly from the dorsal region, have been recovered (Fig. 6). The average centrum length is about $10 \mathrm{~mm}$. A blunt ridge seems to be present on the ventral side of each centrum. Dorsal neural arches measure approximately $24 \mathrm{~mm}$ from articulation with the centrum to the dorsal edge of the spine. All arches are delicate, but do not differ significantly from those of Haptodus garnettensis. Laterally, they are not, or only shallowly, excavated; this also depends on the level of compression. The zygapophyses are short. Unlike in Haptodus garnettensis, the postzygapohyses are widely spaced and single, not showing the broad double-lobed plate as in ROM 43604 or ROM 29872. All diapophyses are moderate lateral extensions and have sub-rounded cross sections. The diapophysial laminae are unreduced, connecting the central edge of the neural arch to the very tip of the diapophysis by a convex blade.

Relatively large intercentra appear to be present between the supraoccipital and one of the posterior coronoids, indicating that Ianthodon has the plesiomorphic tetrapod condition, in contrast to the tendency of reduction of these vertebral elements in advanced pelycosaur-grade sphenacodonts.

No elements posterior to the middle trunk are known, except for a single neural arch with a shortened spine that might belong to the proximal caudal series. The anterior zygapophyses are shortened compared to average dorsal vertebrae, and the spine is half as tall as in the dorsals.

All dorsal ribs are long and weakly curved, with the strongest flexion in the proximal portion. At least one cervical rib is identified with confidence, bearing a straight, stout shaft that flares distally. An anterior process is present on the cervical rib, presumably a plesiomorphic character. In dorsal ribs, the tuberculum is prominent, but not separated from the capitulum by a notch. Like in other basal synapsids, a lamina is present in the dichocephalous rib head, allowing no aperture between the diapophysial lamina and the rib.

Between the cranial elements described by Kissel and Reisz (2004, Figs. 2 and 3), there is one labeled with a question mark. Given the postcranial proportions, it matches the shape and size one would expect for the cleithrum. A flat and broadened dorsal tip instantly turns into a rounder cross section, which is again gradually flattened towards its presumed contact with the clavicle. Similar cleithra are present in Edaphosaurus and Dimetrodon (Romer and Price, 1940, pl. 28 B and 38 C) as well as in Pantelosaurus. It most closely resembles the cleithrum of an undescribed sphenacodont 

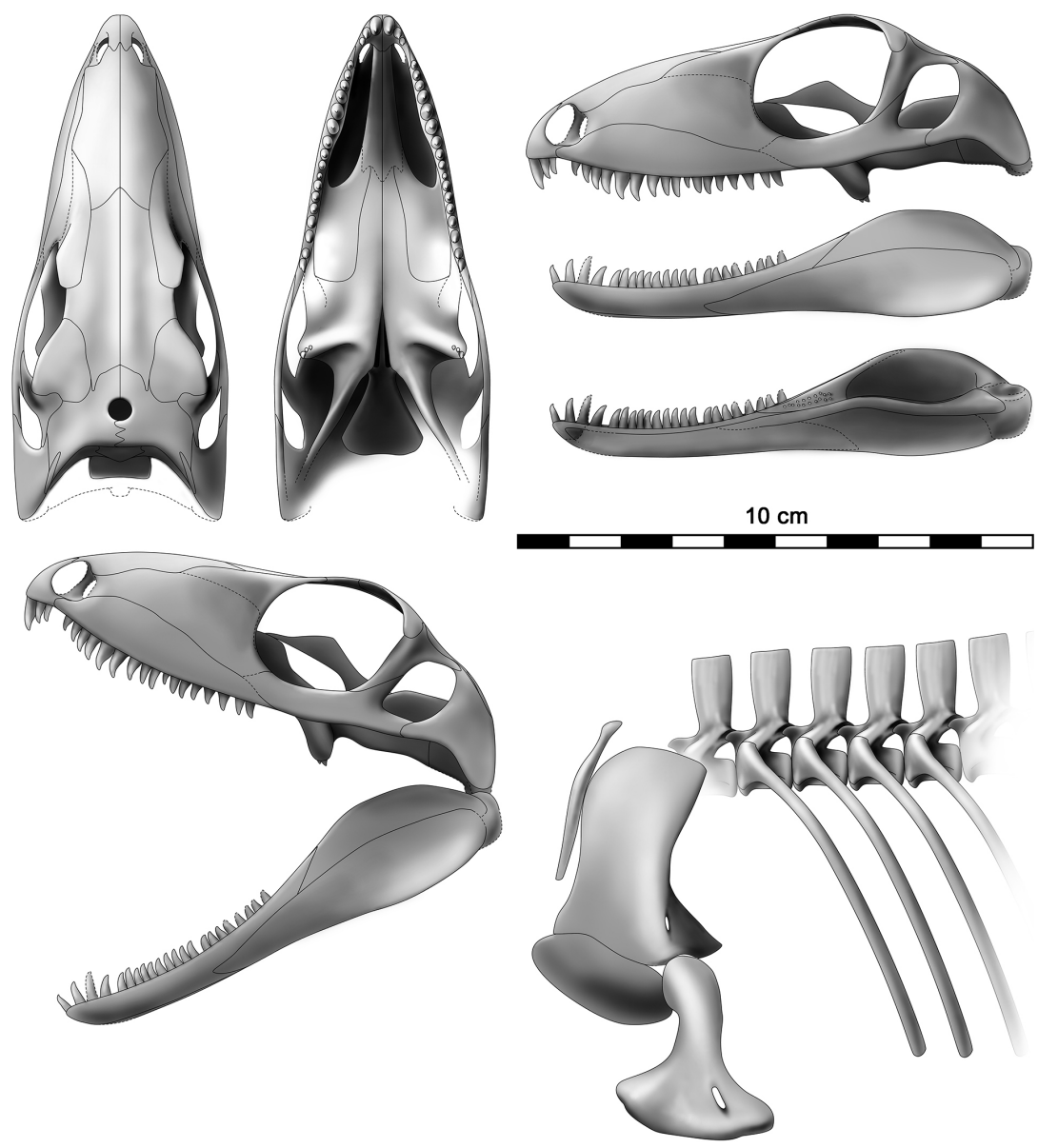

Figure 6. Ianthodon schultzei cranial and skeletal reconstruction. Three-dimensional arrangement and projections based on a wax maquette. Skull in dorsal, ventral and lateral view; mandible in lateral and medial view.

from Garnett, as well as that of the holotype of Haptodus garnettensis RM 14,156.

The replacement bones of the pectoral girdle are delicately constructed and remain unfused in this juvenile specimen. The scapula is $44 \mathrm{~mm}$ tall and $19 \mathrm{~mm}$ wide in midlongitudinal extension. The bone is well-ossified, as is typical for even very young individuals in basal amniotes. As seen in Palaeohatteria, the scapula and anterior coracoid ossify earlier in ontogeny than the posterior coracoid, possibly to support the glenoid fossa. The ontogenetic stage of the holotype of Ianthodon schultzei is between the average condition found in Palaeohatteria longicaudata and that of Haptodus garnettensis, as the scapula and anterior coracoid are still unfused, but the ventral margin of the scapula is fully differentiated and is not as simple as the dorsal end like in Palaeohatteria juveniles. The lateral foramen (supraglenoid foramen) is located above the glenoid fossa, at about one quarter of the total scapular height, and slightly posterior to the edge of the supraglenoid ridge. There is no indication of a notch interrupting the proximal anterior margin. In I. schultzei, the dorsal end of the scapula flares anteroposteriorly, in strong con- trast to the condition in Haptodus garnettensis (compare to Laurin, 1993, Fig. 19). Unfortunately, the distal portion of the juvenile holotype of $H$. garnettensis is not preserved (Currie, 1977, and pers. obs. by F. Spindler). No basal sphenacodontian shows a distally flaring scapula in early ontogeny that is compensated for by further ossification to form a more rectangular outline. Therefore, we assume that the flared scapular blade is an age-independent character of I. schultzei.

The anterior coracoid is a simple oval disc with delicate radiating texture, measuring $32 \times 21.5 \mathrm{~mm}$ along the orthogonal axes.

A left humerus is the only known appendicular element. It measures $53 \mathrm{~mm}$ in length, $8 \mathrm{~mm}$ in mid-diaphysial width and $32 \mathrm{~mm}$ in width at the distal epiphysis. As the specimen is a juvenile, it resembles juvenile specimens of Palaeohatteria. Its proximal head is strongly distorted by crushing, revealing the broken edge of the tubercle for the M. latissimus dorsi and the beginning of the articulation area. The distal end is relatively well-preserved. In typical sphenacodontian fashion, the distal dorsal surface of the bone has an elongate groove on the entepicondyle for the entepicondylar foramen. 
The ectepidondylar ridge on the dorsal surface of the bone is modestly developed. The supinator process, as in Palaeohatteria and other basal sphenacodontians, is a blade-like structure that extends distally without flaring significantly anteriorly. In effect, its anterior edge is nearly parallel to that of the ectepicondylar ridge. In overall shape, it resembles Dimetrodon kempae, Lupeosaurus and Casea (see Romer and Price, 1940, Figs. 31 and 32). There is no evidence that the distal end of the supinator process enclosed an ectepicondylar foramen.

\subsection{Phylogenetic relationships of Ianthodon}

In the original description and phylogenetic analysis of Kissel and Reisz (2004), Ianthodon was found to nest surprisingly high within Sphenacodontia, as a sister taxon to the clade that included Pantelosaurus, Cutleriaand sphenacodontids. In a subsequent, large-scale analysis, Ianthodon was found to be more basal, near the edaphosaurid-sphenacodont node (Benson, 2012), but its exact position remained poorly resolved. In the latter analysis, Benson (2012) extensively revised the character list and included all known "pelycosaur" grade synapsids, while Kissel and Reisz (2004) used data and taxa derived from Laurin (1993), which mainly followed Reisz et al. (1992). Another recent analysis of sphenacodont synapsids by Fröbisch et al. (2011), as part of a description of a new taxon, recovered Ianthodon, Palaeohatteria and Pantelosaurus in an unresolved polytomy.

\subsubsection{Analysis}

The current study intends to analyze the impact of the newly recognized cranial and postcranial elements of Ianthodon schultzei on some aspects of sphenacodontian phylogeny, in particular its relationship to Haptodus garnettensis and Pantelosaurus. Our phylogenetic analysis using the programme PAUP* 4.0b10 (Swofford, 2001) uses all 122 characters employed by Fröbisch et al. (2011) but with some changed terminal taxa. Three taxa used previously have not been included in this analysis.

Palaeohatteria is known from specimens that are much more juvenile (possibly recent hatchlings) than any other basal sphenacodont, and histological samples taken recently support this interpretation. We expect that fossil materials of such an early ontogenetic stage would not assist in resolving tree topology since many osteological features would not be readily comparable with those in adults. In contrast, Ianthodon and other Garnett juveniles are ossified to a much more advanced stage, permitting reliable codings that are largely comparable to the adult morphology of other synapsids. A preliminary phylogenetic analysis that included Palaeohatteria, although supporting the general tree topology discussed in the next section, failed to resolve the pattern of relationships among the basal taxa Ianthodon and Hap- todus garnettensis. The basalmost nodes of Sphenacodontia collapse even in the $50 \%$ majority rule mode, providing no hypothesis to resolve the relative positions of Haptodus garnettensis and Ianthodon. We interpret the situation as follows: the extreme juvenile condition of Palaeohatteria resulted in the coding in a number of osteological features as plesiomorphic, resulting in its placement (minimum height in the tree) between the unresolved basal sphenacodonts (Ianthodon plus Haptodus garnettensis) and the advanced Pantelosaurus saxonicus. We therefore decided to exclude Palaeohatteria from the analysis (compare Laurin, 1993, 1994). Furthermore, there are reasons to consider Pantelosaurus Huene, 1925, as a possible junior synonym of Palaeohatteria Credner, 1888 (Spindler, 2012). With Palaeohatteria included in the current matrix, Sphenacodon is the sister to the other sphenacodontids, and Cutleria is suggested to be haptodont-grade (supported by Laurin, 1993 but not Fröbisch et al., 2011 and Benson, 2012).

Cryptovenator was also removed from the analysis because of its extremely fragmentary nature. The monophyly of Sphenacodontidae is well supported and only three representative taxa are included in this analysis. Therapsid monophyly is extremely well supported, and we include two representative basal taxa. Haptodus garnettensis and other basal sphenacodonts are currently under revision, including an exhaustive phylogenetic analysis; they are thus provisionally cited herein as coded by Laurin (1993), Fröbisch et al. (2011) and Brink and Reisz (2014).

Smaller changes concerning six characters were made in noticeable cases:

Character 43 previously coded state (1) only in Pantelosaurus; thus, it is combined with the former state (2) to the new state (1), which is also supported by the morphology of Pantelosaurus.

Character 48 is set to "?" in Ophiacodontidae as being inapplicable due to character 47 of the same.

Character 51 is corrected to the effect that serration occurs only in some Dimetrodon species and in therapsids, but not in Sphenacodon (Brink and Reisz, 2014).

Character 59 is changed into (0\&1) for Dimetrodon.

Character 70 is affected by retyping only, as state (1) was not used in Fröbisch et al. (2011); thus, it was integrated into $(0)$, while the scoring of sphenacodontids with (2) turns into (1).

Character 97 is partly redundant with character 23 , as the former state (0) means "inapplicable"; the former (0) turns into (?); (1) turns into (0), and (2) turns into (1).

Coding was completely reevaluated for the haptodont-grade taxa Ianthodon, Pantelosaurus and Cutleria, all based on 
detailed specimen reexaminations. The codings for all 122 characters (see Fröbisch et al., 2011, supplement 2) are listed below (brackets mark features that are not fully visible or are based on reconstructions; bold characters indicate rephrased coding):

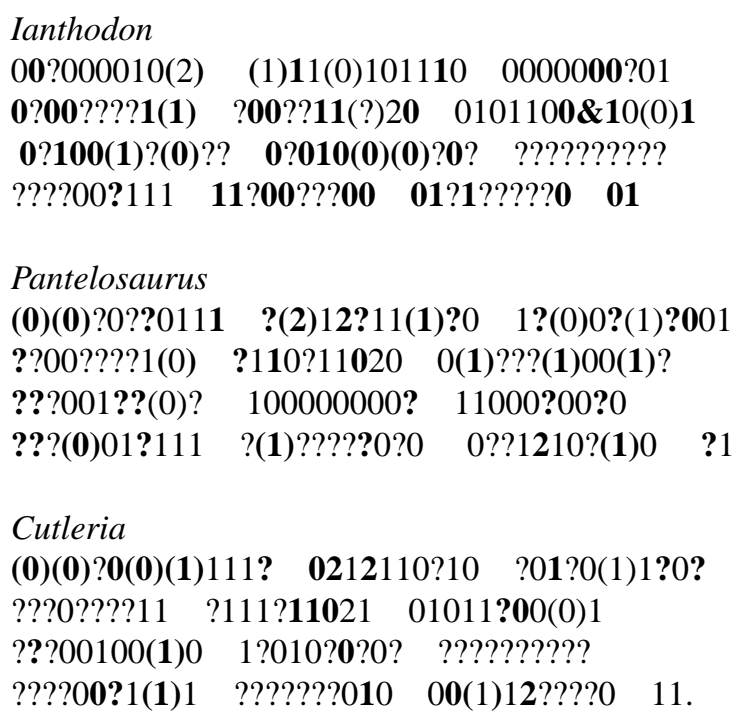

While most deviations from the previous matrix (Fröbisch et al., 2011) concern simple scoring or adding question marks, some changes require comments: character 1: although badly preserved, Pantelosaurus and Cutleria can be scored via reconstruction; character 2: all vague due to poor preservation; Ianthodon changed into (0) to correct a typo in Kissel and Reisz (2004); character 4: Cutleria codes with (0); character 5: the right side of the skull of Cutleria indicates a plesiomorphic condition in the nasal; character 6: Pantelosaurus uncertain, Cutleria by vague indication; character 10: in all three genera; the preservation is bad; Pantelosaurus is coded with (1) regarding the deformation constraints that affected the holotypic fossil; character 11: Pantelosaurus uncertain; Cutleria weakly supported; Ianthodon by vague indication; character 12: depending on the definition, i.e., whether the middle portion of the postorbital is taken into account or not; character 14: Cutleria recoded (formerly "0\&2"); Ianthodon solved via reconstruction; character 18: in the type of Cutleria the bone is broken through; it is thus not able to score, whereas Pantelosaurus indicates it well; character 23: in Cutleria, a small fragment is seen as a maxillary one, leaving no space for the lacrimal (contradicting Lewis and Vaughn, 1965); characters 26 and 27: Ianthodon was known already to resemble $H$. garnettensis; character 28: Pantelosaurus scored from skeleton no. 5 (see von Huene, 1925); Cutleria is much too uncertain; character 31: was previously unknown in Ianthodon; character 33: from pterygoid reconstruction of Ianthodon; character 34: follows reconstructions in all cases; character 56: if meaning a maxillary swelling only, it is seen in the Pantelosaurus skeleton no. 4 (see von Huene, 1925); character 57: Cutle- ria newly scored; Ianthodon depends on (differing) referred maxillaries; character 62: remaining questionable in all three taxa, Cutleria and Pantelosaurus were mistakenly scored in previous matrix; character 66: Ianthodon, although affected from compaction, is tentatively seen as resembling $H$. garnettensis; character 69: Cutleria scored with (1); state (2) not applied since Laurin (1993); character 74: although juvenile, Ianthodon clearly differs from $H$. garnettensis; character 77: Ianthodon scored from reconstructed cleithrum position; character 89: like in other characters, the preservation of Pantelosaurus was previously evaluated too optimistically, especially in the femur; character 94: the Pantelosaurus type preserves about half of its pedal elements, sufficient to reconstruct an unreduced state; character 105: Ianthodon resembled the condition seen in Varanosaurus (Berman et al., 1995), although subject to compaction.

The data set was analyzed with the branch-and-bound parsimony algorithm of PAUP* 4.0b10 (Swofford, 2001). All characters are unordered and of equal weight; multiple codings were treated as polymorphisms, as this adjustment includes the possibility of uncertainties. According to Strong and Lipscomb (1999), missing and inapplicable data were both coded by "?". The Bremer decay values were calculated stepwise. Bootstrap values were run with 1000 replicates but with a branch-and-bound setting (no addition sequence replicates in the present study).

\subsubsection{Results}

The branch-and-bound search of the final matrix retained the 10 most parsimonious trees, with a tree length of 245 steps. The consistency index (ci) is 0.793 (0.788 without uninformative characters). The retention index (RI) is 0.798 , leading to a rescaled consistency index (RC) of 0.632. Comparing the previous trees (Kissel and Reisz, 2004; Fröbisch et al., 2011; Benson, 2012) the overall topology is similar in the current result (Fig. 7), with very robust support values.

For diagnostic features, a character change that is both unequivocal and unambiguous is preferred. Additional support is mentioned if the ci is 1.0 in ambiguous character histories or higher than 0.5 in unambiguous cases. Character numbers, according to Fröbisch et al. (2011, Supplement 2) are noted in brackets.

The strict consensus shows the position Ianthodon one node lower than concluded by Fröbisch et al. (2011). Among the 10 retained trees, the alternate topologies suggested both Ianthodon schultzei and Haptodus garnettensis as potential basalmost sphenacodonts. Resolving their exact positions is impossible in the strict consensus, while the majority rule consensus supports a more basal position for Ianthodon, with $60 \%$ frequency. In this scenario, Haptodus garnettensis and higher Sphenacodontia share the diagnostic feature of a supracanine buttress (character 21) and an anteroventrally sloping premaxillary margin (96: $\mathrm{ci}=0.667)$. If $H$. garnettensis is more basal, Ianthodon and 
higher taxa share a deep supratemporal notch on the parietal (15; the supporting steps of characters 32 and 93 are reconstructed and ambiguous). The shallow supratemporal notch in H. garnettensis is accepted from Laurin (1993) for the time being, subject to reevaluation. The maxillary character (21) provides a more objective and comparable feature that reflects a known evolutionary trend of pelycosaur-grade sphenacodonts. Furthermore, Ianthodon appears to be the only known sphenacomorph to share an untwisted prearticular with more basal synapsids. This leads to the preferred hypothesis of Ianthodon being more basal (partly according to Benson, 2012), supported also by character discussion.

For both cases, Ianthodon is diagnosed by a postfrontal which is posteriorly incised by the postorbital (11: $\mathrm{ci}=0.667$, convergent to Sphenacodontidae). Further diagnostic features, such as the reduced dentition (see above), have lower ci values, at least according to the character list used in this study. By differential diagnosis, Ianthodon can be identified by a lack of many apomorphies. Also, independently from its position in the tree, Haptodus garnettensis is diagnosed by the autapomorphies of a facial exposure of the septomaxilla (3) (which is small but present) and a deep and low scapulocoracoid notch (76), and it is supported by a double splenial-angular overlap $(45$ : ci $=0.8$, similar to Sphenacodon).

\subsubsection{Taxonomy}

In all phylogenetic analyses carried out so far (Brinkman and Eberth, 1983; Reisz et al., 1992, and followers; Benson, 2012), the node for the sister-group relationship between Edaphosauridae and Sphenacodontia is stable, and the robustness of this taxon warrants taxonomic designation. Although remaining unnamed for a long time, the new term Sphenacomorpha was applied to this clade by Ivakhnenko without a definition (Ivakhnenko, 2003, p. 358). We therefore define this well-supported clade by the last common ancestor of Edaphosaurus pogonias Cope, 1882 and Homo sapiens Linnaeus, 1758. Providing a proper definition of this clade is particularly appropriate here since the Garnett representatives of Sphenacomorpha, Ianthodon, Ianthasaurus and Haptodus are basal representatives of the two branches that are at this node. Localities like Badger Creek (Sumida and Berman, 1993) and Garnett (Kissel and Reisz, 2004) are key sites for investigations of the initial diversification of Sphenacomorpha.

Among the historical designations previously used for basal synapsids, the recent usage of the term "Theromorpha" as a senior synonym of the generally accepted Therapsida by Ivakhnenko (2008, resembling the usage by Nopcsa ( 1923); compare also Ivakhnenko, 2003) is a notable case. First used by Cope (1878) to combine Pelycosauria and Anomodontia, the term "Theromorpha" was subsequently ignored (Osborn, 1903). It was later resurrected, e.g., in Williston (1912), but was always broader than Pelycosauria. Williston abandoned his use of "Theromorpha" in later classifications (Romer and Price, 1940). In the preface of their great revision, Romer and Price (1940) preferred the term "Pelycosauria" to "Theromorpha", understood as synonymous. Therefore, the usage of this term yields confusion and should remain unused in a modern taxonomic framework (C. Kammerer, personal communication, 2014).

According to our current analysis, the node-based taxon Sphenacomorpha is diagnosed by the following unambiguous and unequivocal characters:

postorbital posterior process goes from broad to narrow (character 13);

quadratojugal loses zygomatic component (30);

stapes changes from massive to blade-like 38);

coronoid region strongly arching dorsally (39);

ilium loses dorsal groove (81);

ilium expanding anterodorsally (82);

pterygoid quadrate process loses medial shelf (102);

stapes dorsal goes from slender to broad (103).

The taxon is additionally supported by the following unequivocal but ambiguous characters: posterior part of surangular curving ventrally (46); pterygoid teeth in two rather than three groups (107); elongate calcaneum (119).

Furthermore, there are also unambiguous characters with ci greater than 0.5: frontal orbital process from absent to weakly developed ( 8 : $\mathrm{ci}=0.8$ ); position of pineal foramen from posterior to more anterior position (17: ci $=0.667)$.

The clade Sphenacodontia is further diagnosed by the following unambiguous and unequivocal characters: ridged pineal rim (18), marginal teeth from slender to robust (49), deep sockets for premaxillary teeth (52). It is also supported by the unequivocal but ambiguous character of an enlarged triceps process in the posterior coracoids (113).

The clade name Sphenacodontoidea is maintained. It is defined herein as a node-based taxon (originally stem-based; Reisz et al., 1992) and as the last common ancestor of Sphenacodon ferox Marsh, 1878 and Homo sapiens Linnaeus, 1758. The taxon Sphenacodontidae remains stembased and includes Cutleria, according to Benson (2012) and the present analysis and in contrast to former studies. The classical large-bodied genera Dimetrodon, Ctenospondylus, Sphenacodon and their close kin are combined in the nodebased group Sphenacodontinae, with the content accepted since Romer and Price (1940).

\section{Discussion and conclusions}

The new information on the morphology of Ianthodon confirms its basal position within Sphenacodontia. Together with 


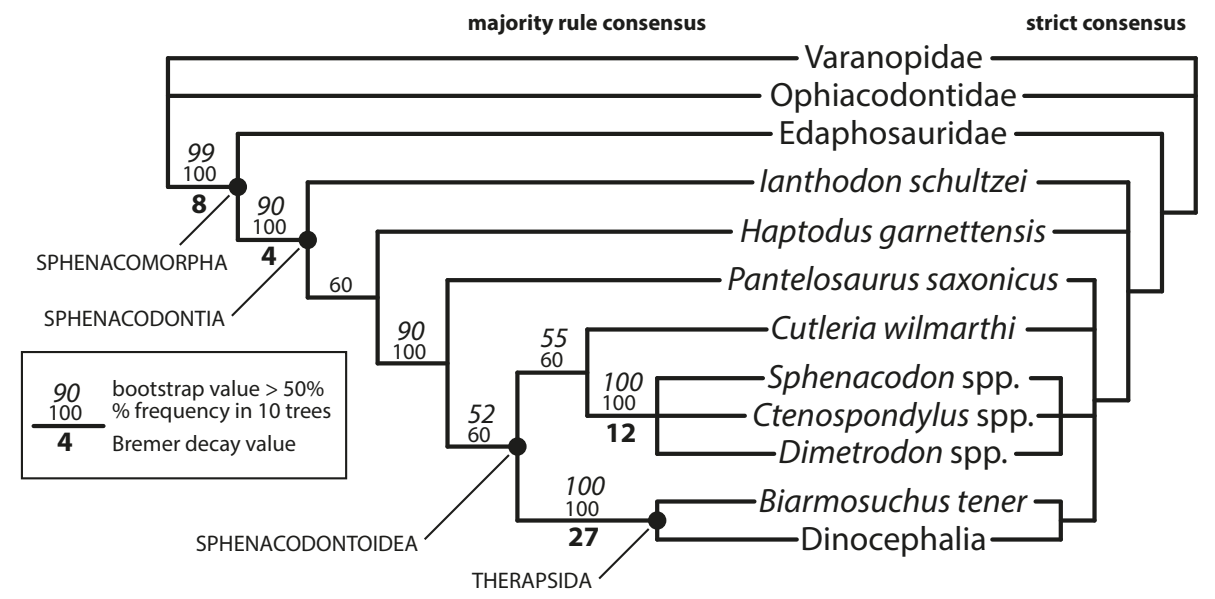

Figure 7. Majority rule and strict consensus cladograms of the 10 most parsimonious trees, with a key for bootstrap values above $50 \%$, the frequency of node occurrence and Bremer decay values. For nodes that collapse at one extra step, the Bremer decay values are not shown.

other forms from the Garnett fossil lagerstaette, it represents one of the oldest faunas close to the initial radiation of Sphenacomorpha, including the edaphosaurid Ianthasaurus and the basal sphenacodont Haptodus garnettensis. The osteology of these taxa provides valuable information about the plesiomorphic condition associated with the evolution of Sphenacomorpha, the large clade that includes mammals. At the same time, the variation among these Missourian-aged taxa includes rather advanced features that reoccur in higher sphenacodonts, the most noticeable being the small number of premaxillary and precaniniform teeth in Ianthodon. Based on the available evidence, we propose that basal sphenacomorphs descended from a generalist form with a great potential for adaptions, evolving into ecologically divergent species with small-scale differences (Spindler et al., 2013). Despite the new data on Ianthodon, we still know relatively little about this early stage of sphenacomorph evolution, and further study of the Garnett fauna might greatly increase the understanding of this stage of amniote diversification. The available evidence suggests that Ianthodon may represent, in many features, the primitive condition of sphenacodonts, but additional studies of other members of this clade are required for a better understanding of this stage of synapsid evolution.

The results of the phylogenetic analysis are not unexpected. Sphenacodontids clearly date back to the Pennsylvanian of North America as well as central Europe (Sumida and Berman, 1993; Harris et al., 2004; Štamberg and Zajíc, 2008). The dichotomy of Sphenacodontoidea therefore occurred within the Carboniferous, contradicting a frequently presented simplified picture (e.g., Liu et al., 2009, Fig. 3) of this stage of synapsid evolution.

Author contributions. F. Spindler carried out the drawing documentation, taxonomic recognition and description as well as the phylogenetic analysis. D. Scott and R. R. Reisz discussed the ongoing work and made corrections. D. Scott carried out addi- tional preparation and took photographs. F. Spindler prepared the manuscript, to which all authors contributed and which all authors discussed.

The Supplement related to this article is available online at doi:10.5194/fr-18-17-2015-supplement.

Acknowledgements. We would like to thank Jörg W. Schneider (Technische Universität Bergakademie Freiberg, Germany) and Martin Sander (Rheinische Friedrich-Wilhelms-Universität Bonn, Germany) for discussion and substantial support. Nico Schendel (Freiberg) assisted in the skull reconstruction, using a wax model. During the review process, we received numerous suggestions from Spencer G. Lucas (New Mexico Museum of Natural History and Science, Albuquerque) and Florian Witzmann (Museum für Naturkunde Berlin, Germany) and obtained especially helpful feedback from Christian Kammerer (Berlin). We are grateful for financial support from the Deutsche Forschungsgemeinschaft (SCHN 408/20-1) and NSERC (Canada).

Edited by: F. Witzmann

Reviewed by: S. G. Lucas and C. Kammerer

\section{References}

Benson, R. B. J.: Interrelationships of basal synapsids: cranial and postcranial morphological partitions suggest different topologies, J. Syst. Palaeontol., 10, 601-624, 2012.

Berman, D. S., Reisz, R. R., Bolt, J. R., and Scott, D.: The cranial anatomy and relationships of the synapsid Varanosaurus (Eupelycosauria: Ophiacodontidae) from the Early Permian of Texas and Oklahoma, Ann. Carnegie. Mus., 64, 99-133, 1995.

Brink, K. S. and Reisz, R. R.: Hidden dental diversity in the oldest terrestrial apex predator Dimetrodon, Nature Communications, 5, 3269, doi:10.1038/ncomms4269, 2014. 
Brinkman, D. and Eberth, D. A.: The Interrelationships of Pelycosaurs, Breviora, 473, 1-35, 1983.

Cope, E. D.: The Theromorphous Reptilia, Am. Nat., 12, 829-830, 1878.

Currie, P. J.: A new haptodontine sphenacodont (Reptilia: Pelycosauria) from the Upper Pennsylvanian of North America, J. Paleontol., 51, 927-942, 1977.

Credner, H.: Die Stegocephalen und Saurier aus dem Rothliegenden des Plauen'schen Grundes bei Dresden, vii. Theil: Palaeohatteria longicaudata CRED, Z. Deut. Geol. Ges., 40, 490-558, 1888.

Eberth, D. A.: The skull of Sphenacodon ferocior, and comparisons with other sphenacodontines (Reptilia: Pelycosauria), New Mexico Bureau of Mines and Mineral Resources, Circular, 190, 1-39, 1985.

Fröbisch, J., Schoch, R. R., Müller, J., Schindler, T., and Schweiss, D.: A new basal sphenacodontid synapsid from the Late Carboniferous of the Saar-Nahe Basin, Germany, Acta Palaeontol. Pol., 56, 113-120, 2011.

Harris, S. K., Lucas, S. G., Berman, D. S., and Henrici, A. C.: Vertebrate fossil assemblage from the Upper Pennsylvanian Red Tanks member of the Bursum Formation, Lucero uplift, Central New Mexico, in: Carboniferous-Permian transition, edited by: Lucas, S. G. and Zeigler, K. E., New Mexico Museum of Natural History and Science Bulletin, 25, 267-283, 2004.

Huene, F.: Ein neuer Pelycosaurier aus der unteren Permformation Sachsens, Geologische und Paläontologische Abhandlungen, 14, 215-263, 1925.

Ivakhnenko, M. F.: Eotherapsids from the East European Placket (Late Permian), Paleontol. J., 37, S339-S465, 2003.

Ivakhnenko, M. F.: Cranial Morphology and Evolution of Permian Dinomorpha (Eotherapsida) of Eastern Europe, Paleontol. J., 42, 859-995, 2008.

Kemp, T. S.: Mammal-like Reptiles and the Origin of Mammals, Academic Press, New York, 1982.

Kissel, R. A. and Reisz, R. R.: Synapsid fauna of the Upper Pennsylvanian Rock Lake Shale near Garnett, Kansas and the diversity pattern of early amniotes, in: Recent Advances in the Origin and Early Radiation of Vertebrates, edited by: Arratia, G., Wilson, M. V. H., and Cloutier, R., Verlag Dr. F. Pfeil, München, 409-428, 2004.

Laurin, M.: Anatomy and Relationships of Haptodus garnettensis, a Pennsylvanian synapsid from Kansas, J. Vertebr. Paleontol., 13, 200-229, 1993.

Laurin, M.: Re-evaluation of Cutleria wilmarthi, an early Permian synapsid from Colorado, J. Vertebr. Paleontol., 14, 134-138, 1994.

Lewis, G. E. and Vaughn, P. P.: Early Permian Vertebrates from the Cutler Formation of the Placerville Area, Colorado, Geol. Surv. Prof. Paper, 503-C, C1-C50, 1965.

Liu, J., Rubidge, B., and Li, J.: New basal synapsid supports Laurasian origina for therapsids, Acta Palaeontol. Pol., 54, 393400, 2009.

Mazierski, D. M. and Reisz, R. R.: Description of a new specimen of Ianthasaurus hardestiorum (Eupelycosauria: Edaphosauridae) and a re-evaluation of edaphosaurid phylogeny, Can. J. Earth Sci., 47, 901-912, 2010.
Modesto, S. P. and Reisz, R. R.: A new skeleton of lanthasaurus hardestii, a primitive edaphosaur (Synapsida: Pelycosauria) from the Upper Pennsylvanian of Kansas, Can. J. Earth Sci., 27, 834844, 1990.

Nopcsa, F.: Die Familien der Reptilien, Fortschritte der Geologie und Paläontologie, 2, 1-210, 1923.

Osborn, H. F.: The reptilian subclasses Diapsida and Synapsida and the early history of the Diaptosauria, Memoirs of the American Museum of Natural History, 1, 449-507, 1903.

Reisz, R. R.: Petrolacosaurus, the Oldest Known Diapsid Reptile, Science, 196, 1091-1093, 1977.

Reisz, R. R.: A Diapsid Reptile from the Pennsylvanian of Kansas, Special publication of the Museum of Natural History, University of Kansas, 7, 1-74, 1981.

Reisz, R. R.: Pelycosauria, Handbuch der Paläoherpetologie, Teil 17, A. Gustav Fischer Verlag, Stuttgart, 1986.

Reisz, R. R. and Berman, D. S.: Ianthasaurus hardestii n. sp., a primitive edaphosaur (Reptilia, Pelycosauria) from the Upper Pennsylvanian Rock Lake Shale near Garnett, Kansas, Can. J. Earth Sci., 23, 77-91, 1986.

Reisz R. R., Heaton, M. J., and Pynn, B. R.: Vertebrate fauna of Late Pennsylvanian Rock Lake Shale near Garnett, Kansas: Pelycosauria, J. Paleontol., 56, 741-750, 1982.

Reisz, R. R., Berman, D. S., and Scott, D.: The cranial anatomy and relationships of Secodontosaurus, an unusual mammal-like reptile (Synapsida: Sphenacodontidae) from the early Permian of Texas, Zool. J. Linn. Soc.-Lond., 104, 127-184, 1992.

Romer, A. S. and Price, L. I.: Review of the Pelycosauria, Geol. S. Am. S., 28, 1-538, 1940.

Spindler, F.: Die sphenacodonten Pelycosaurier Europas, Abstract Volume of the Centenary Meeting of the Paläontologische Gesellschaft, Terra Nostra, 3, 171 pp., 2012.

Spindler, F., Brink, K., and Piñeiro, G.: An upgraded perspective on basal Sphenacodontia, the stem group of mammal-like amniotes, in: Palaeobiology and Geobiology of Fossil Lagerstätten through Earth History, edited by: Reitner, J., Yang, Q, Wang, Y., and Reich, M., Joint Conference of the Paläontologische Gesellschaft and the Palaeontological Society of China (abstract volume), Göttingen, 157 pp., 2013.

Štamberg, S. and Zajíc, J.: Carboniferous and Permian faunas and their occurence in the limnic basins of the Czech Republic, Muzeum východních Čech v Hradci Králové, 2008.

Strong, E. E. and Lipscomb, D.: Character Coding and Inapplicable Data, Cladistics, 15, 363-371, 1999.

Sumida, S. S. and Berman, D. S.: The Pelycosaurian (Amniota: Synapsida) assemblage from the late Pennsylvanian Sangre de Cristo Formation of central Colorado, Ann. Carnegie Mus., 62, 293-310, 1993.

Swofford, D. L.: PAUP*: Phylogenetic Analysis Using Parsimony, Sinauer Associates, Sunderland, MA, 2001.

Williston, S. W.: Primitive reptiles, J. Morphol., 23, 637-666, 1912. 